Original Article

\title{
THE EFFECT OF HEALTH EDUCATION AS NON-PHARMACOLOGICAL THERAPY ON PHYSICAL FITNESS, BLOOD CHEMISTRY AND BRAIN FUNCTION AMONG SENIOR CITIZEN IN BOTH RURAL AND URBAN AREAS OF BALI, INDONESIA
}

\author{
I PUTU GEDE ADIATMIKA ${ }^{*}$, KOJI TERASAWA ${ }^{2}$, SUCHINDA JARUPAT MARUO ${ }^{3}$, KEISUKE NAKADE ${ }^{2}$, TOSHIAKI \\ WATANABE $^{4}$, SAIKI TERASAWA ${ }^{5}$, TOSHIE KOBAYASHI ${ }^{6}$, YONG ZHANG ${ }^{7}$, KOKI NAKAJIMA ${ }^{6}$, FUMIHITO SASAMORI ${ }^{5}$
}

1Department of Physiology Udayana University, Faculty of Medicine, JI. PB Sudirman, Denpasar-Bali, Indonesia, 2Shinshu University Graduate School of Medicine 3-1-1 Asahi, Matsumoto, Nagano 3908621 Japan, ${ }^{3}$ Department of Occupational Health and Safety, Faculty of Public Health, Mahidol University, 420/1 Ratchathewi, Bangkok 10400, Thailand. ${ }^{4}$ Shinshu University Faculty of Education 6-Ro Nishinagano, Nagano, 3808544, Japan, ${ }^{5}$ Shinshu University Faculty of Engineering 4-17-1 Wakasato, Nagano, 3808553, Japan, ${ }^{6}$ Matsumoto University Niimura 2095-1, Matsumoto, Nagano, 3901295 Japan, ${ }^{7}$ The University of Nagano 8-49-7 Miwa Nagano, 3808525

"Email: ipgadiatmika@unud.ac.id

Received: 03 Nov 2020, Revised and Accepted: 26 Dec 2020

ABSTRACT

Objective: The population of senior citizens has increased and needs more care for the quality of life. Health education is a non-pharmacological therapy to improve physical fitness, blood chemistry and brain function. This research was performed to evaluate the effect of health education on the physical fitness, blood chemistry and brain function of senior citizens in rural and urban Bali.

Methods: A total of 60 people aged $67.9 \pm 1.2$ y were recruited from Tabanan, Indonesia, and 72 people aged $67.3 \pm 0.6$ y were recruited from Denpasar, Indonesia. The health education program lasted 8 mo, used Japanese-style healthcare modified for the Balinese culture, and measured physical fitness, blood chemistry, and brain function before and after the educational period.

Results: The average number of steps in Tabanan was 4247.2 \pm 98.9 , and those in Denpasar were $4336.1 \pm 102.4$. The weight and waist circumference were not significantly different between the Tabanan and Denpasar samples. The physical fitness of senior citizens in Tabanan and Denpasar improved significantly. Blood chemistry in the Tabanan sample was not significantly different after the program. In Denpasar, High-Density Lipoprotein and Low-Density Lipoprotein significantly improved. Brain function was significantly improved after the program.

Conclusion: Health education using Japanese-style healthcare programs based on Balinese culture as non-pharmacological therapy has beneficial effects on physical fitness, blood chemistry and brain function in senior citizens in both urban and rural areas in Bali, Indonesia. It is suggested that senior citizens should continue our health education program to maintain their health.

Keywords: Health education, Physical fitness, Blood chemistry, Senior citizens

(C) 2021 The Authors. Published by Innovare Academic Sciences Pvt Ltd. This is an open access article under the CC BY license (https://creativecommons.org/licenses/by/4.0/) DOI: https://dx.doi.org/10.22159/ijpps.2021v13i2.40151. Journal homepage: https://innovareacademics.in/journals/index.php/ijpps.

\section{INTRODUCTION}

The population of senior citizens has increased due to changes in economic and welfare development. In Bali, the number of senior citizens has increased. Moreover, global changes have affected lifestyle, such as shifts from more activity to sedentary behavior, regardless of rural or urban residence area. The Balinese Health Profile reported that there are more than 4.1 million Balinese people, and senior citizens accounted for approximately $7.3 \%$ [1].

Some effects of lifestyle changes related to the aging process on senior citizens and the risk of emerging non-communicable diseases should be considered. Everyone should monitor their condition regularly to maintain physical fitness and maintain blood chemistry and brain function in a normal state. Some studies have shown that the aging process can be delayed and physical fitness can be increased by performing routine physical activity. Moreover, good physical fitness can maintain brain function and blood chemistry [2,3]. Physical activity is important in the context of non-communicable disease prevention [4] Both parameters are related to body metabolism and the ability of the brain to maintain its function to perform its tasks for daily life.

Studies have shown that the physical fitness of senior citizens can be achieved by participating in physical activities such as exercising, walking, running, and dancing. The most important consideration is that regular activities should be performed every day and should be done regularly. Physical activity surveillance from 122 countries showed that $31.1 \%$ of people in Southeast Asia were inactive [5]. Indonesia was included in this data. This means that activities should be programmed and done regularly at the appropriate duration, frequency and intensity.

Performing regular physical activity is rare among senior citizens in Bali. Senior citizens commonly change their activities from hard work to pleasure work. This change was a risk factor for decreased physical fitness, brain function and body metabolism. Therefore, physical education is needed to encourage senior citizens to perform their activities and to be used as a non-pharmacological approach to maintain physical fitness. Continued improvement in monitoring physical activity at the population level can help guide the development of policies and programs to increase physical activity and reduce the burden of noncommunicable diseases in the $21^{\text {st }}$ century [6-11]. Cancer is an example of a condition that can be prevented through active physical activity [12]. Therefore, senior citizens must perform physical activity in daily life.

Recently, there have been no data about the promotion of physical activity in Bali. Available data have shown that globally, one-third of adults and four out of five adolescents do not meet the public health recommendation for the level of physical activity [5, 13]. This guideline needs to be met by senior citizens, including those in Bali.

Senior citizens in Bali in particular or Indonesia, in general, were organized by the government into senior citizen organizations called Kelompok Lanjut Usia or Lansia. This group was organized into one group for one village and received a special program from the Public Health Centre or PHC located in urban or rural areas in Bali. This program was arranged by integrating health education based on Balinese culture that is familiar to senior citizens $[14,15]$. 
Physical education has been applied in many ways, including a Japanese-style healthcare program. This program has been implemented in several countries and acquired ISO 9001:2008 (International Organization for Standardization). Its effectiveness in health education in Bali, Indonesia, is still debated. In particular, it can be beneficial to implement health promotion efforts in Bali, Indonesia, that incorporate components of programs from other countries.

This research was performed to evaluate the effect of health education on the physical fitness, blood chemistry and brain function of rural and urban senior citizens in Bali.

\section{MATERIALS AND METHODS}

The study was performed in Tabanan Regency and Depasar City in Bali, Indonesia. Both areas were represented by one village that has
Kelompok Lanjut Usia, a senior citizen organization. The village was chosen based on the best rank of senior citizen organization in Bali and because it was representative of rural and urban areas. The study was done for 8 mo.

A total of 60 people aged $67.9 \pm 1.2$ y were recruited from Tabanan, Indonesia, and a total of 72 people aged $67.3 \pm 0.6$ y were recruited from Denpasar, Indonesia. Both groups received health education consisting of physical education every week, such as exercise, fun walking $5 \mathrm{~km}$, and social activities based on Balinese culture, including dancing and singing (fig. 1). The health program lasted 8 mo, and everyone was equipped with a pedometer. Before and after the program, their energy expenditure was measured using a pedometer, anthropometric measurements were obtained, go/no-go tasks were used for the brain function assessment, and physical fitness tests and blood chemistry tests were performed (fig. 2).
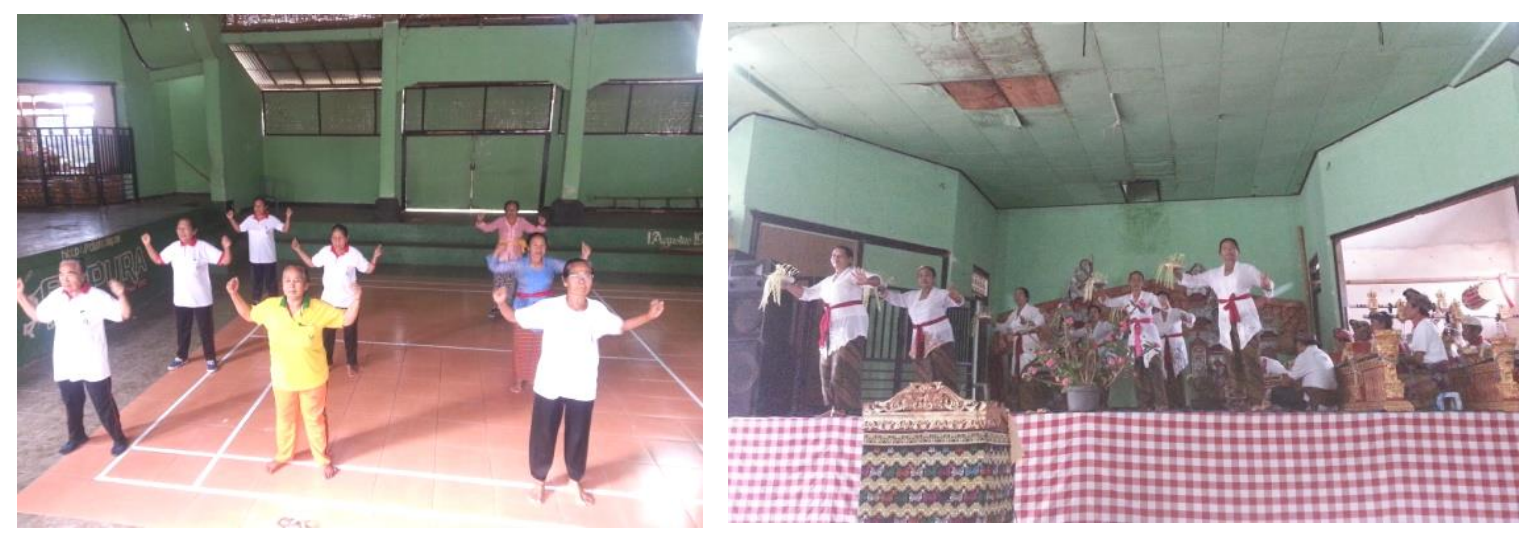

Fig. 1: Physical activity through exercise (left) and Balinese dance (right)
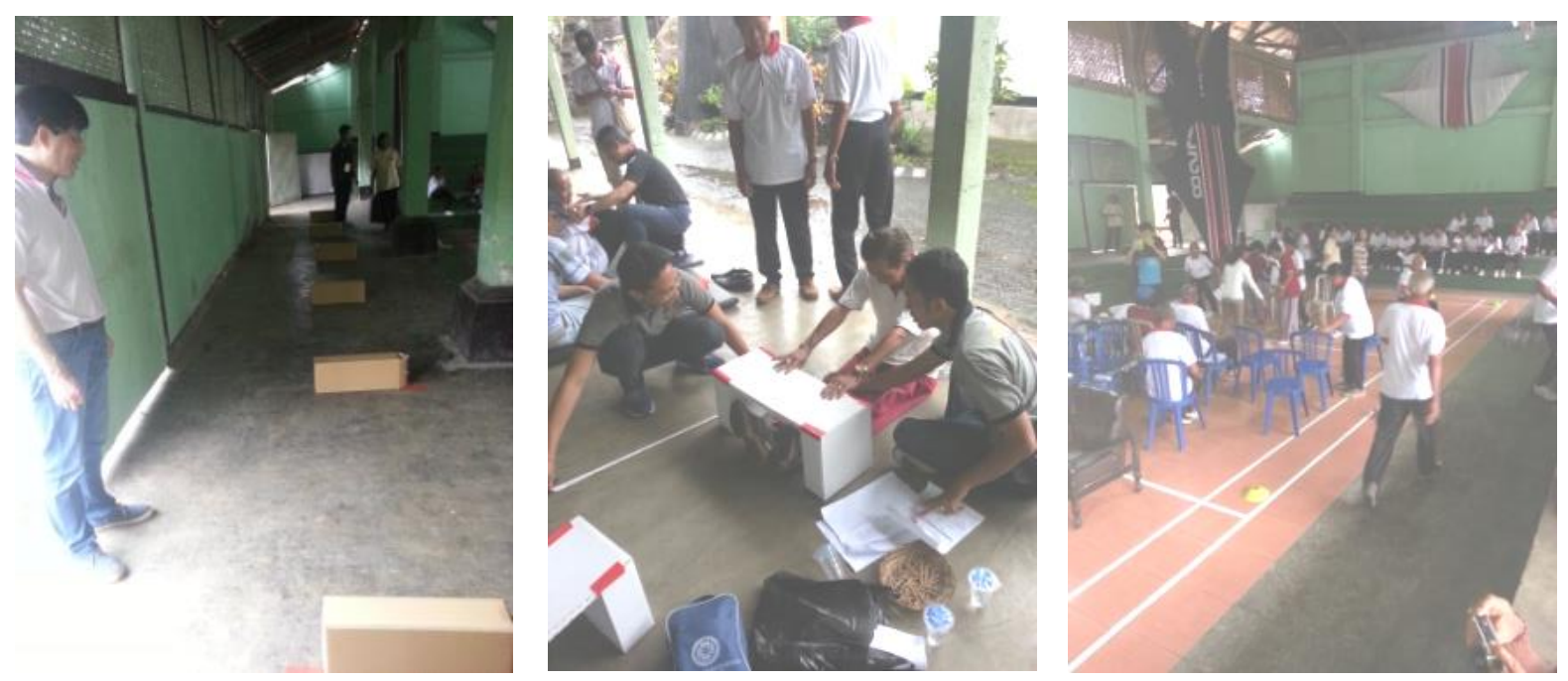

Fig. 2: Physical fitness test using a $10 \mathrm{~m}$ obstacle walk (left), sit-reach test (middle) and 6-min walk (right)

\section{RESULTS AND DISCUSSION}

There were 60 people in Tabanan and 72 people in Denpasar. The average ages were $67.9 \pm 1.2 \mathrm{y}$ in Tabanan and $67.3 \pm 0.6 \mathrm{y}$ in Denpasar, Indonesia. The type of test was accommodated to senior citizens who have limitations for some activities. is the program was designed according to physical activity recommendations for senior citizens. The intensity of aerobic activity takes into account older adults' aerobic fitness; activities that maintain or increase flexibility are recommended, and balance exercises are recommended for older adults at risk of falls [16]. Physical education should be provided to make people aware of an appropriate program for physical activities. In Bali, some activities were performed related to culture that made senior citizens more appreciated by younger people. Balinese dance and singing were performed as social activities for senior citizens in Bali. These activities require proper physical fitness for $30 \mathrm{~min}$ of dancing and $30 \mathrm{~min}$ of singing.

Anthropometry data were assessed using weight, body mass index (BMI) and waist circumference (table 1). Table 1 shows that anthropometry data of the groups from each area after the health education program were not significantly different $(p>0.05)$. Anthropometry measurements (weight and waist circumference) were not significantly different between Tabanan and Denpasar. However, the average BMI of the Denpasar City group was greater than that of Tabanan regency. Denpasar City is located in central 
Bali, where many activities are performed using motorbikes and cars, while in Tabanan Regency, most residents perform activities by walking.

The other means to assess obesity is the waist-hip ratio (WHR). The waist-to-hip ratio of the Tabanan Regency group was higher than that of the Denpasar City group. The health program had no effect to reduce WHR. This result could be affected by nutrition intake during the program. WHR in general, has emerged as an important risk factor for several chronic diseases, but little quantitative information exists about its relationship with energy intake and expenditure in men and women. This result is similar to that of a study in a middle European urban population that studied health risks in association with BMI and WHR using 3D laser scanning [17]. Because the WHR is an important predictor of several cardiovascular and other chronic diseases, documentation of a strong effect of physical activity on the WHR selectively in men may provide a partial explanation of how the effect of physical activity is mediated and why physical activity is more effective in men than in women in reducing disease risk [18].

Table 1: Characteristics of participants in Tabanan and Denpasar, Bali, Indonesia

\begin{tabular}{|c|c|c|c|c|c|c|c|}
\hline & & Tabanan & & P-value & Denpasar & & P-value \\
\hline & & Before & After & & Before & After & \\
\hline 1. & Weight (kg) & $59.7 \pm 1.1$ & $60.8 \pm 1.3$ & 0.537 & $57.7 \pm 1.5$ & $58.5 \pm 1.7$ & 0.278 \\
\hline 2. & BMI & $22.8 \pm 0.4$ & $23.9 \pm 0.5$ & 0.020 & $23.2 \pm 0.5$ & $24.1 \pm 0.6$ & 0.013 \\
\hline 3. & $\begin{array}{l}\text { Waist } \\
\text { Circumference }(\mathrm{cm})\end{array}$ & $85.4 \pm 1.2$ & $84.9 \pm 1.6$ & 0.625 & $81.5 \pm 1.3$ & $81.4 \pm 1.5$ & 0.754 \\
\hline
\end{tabular}

Another study reported that BMI, waist circumference, and WHR show comparable positive associations with colon cancer risk reduction in men. Associations between anthropometric measures and colon cancer are weak or null in women, but there is some evidence of effect modification by hormone replacement therapy $[19,20]$. This means that physical activities need to be performed regularly to obtain BMI, WC and WHR reduction to prevent diseases. Physical education for senior citizens made them aware of the need to perform regular physical activities. Some activities were performed, but in this study, there was no impact on parameters, such as waist circumference, BMI and weight, after 8 mo.

Physical activity was recorded using a pedometer. The results in Tabanan showed that the average number of steps was $4247.2 \pm 98.9$, and in Denpasar, the average number of steps was $4336.1 \pm 102.4$ (fig. 3).

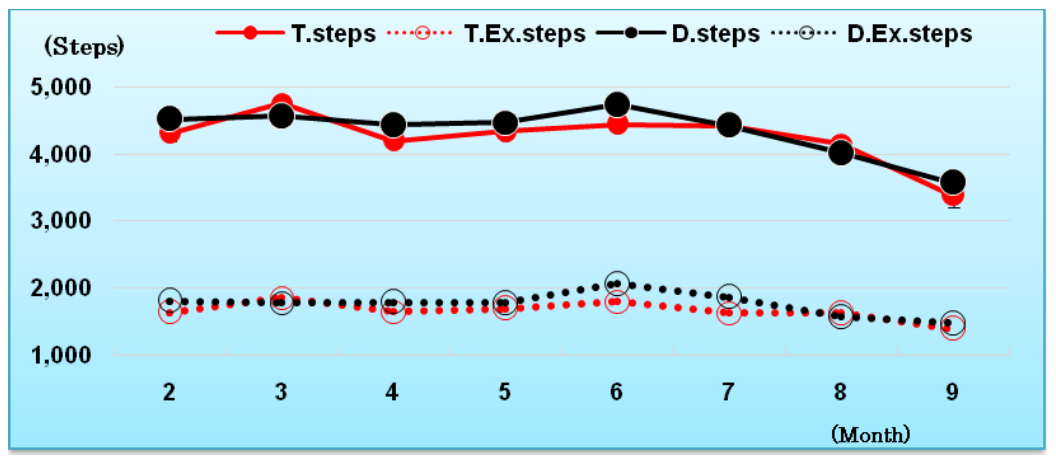

Fig. 3: Walking and exercise steps

Table 2: Comparison of before and after health education in Tabanan and Denpasar

\begin{tabular}{|c|c|c|c|c|c|c|c|c|c|}
\hline & \multirow[t]{2}{*}{ T/B } & \multirow[t]{2}{*}{$\mathbf{T} / \mathbf{A}$} & \multirow[t]{2}{*}{ P-value } & \multirow[t]{2}{*}{ D/B } & \multirow[t]{2}{*}{$\mathbf{D} / \mathbf{A}$} & \multirow{2}{*}{$\begin{array}{l}P \text { - } \\
\text { Value }\end{array}$} & \multicolumn{3}{|c|}{ Two way ANOVA } \\
\hline & & & & & & & $\mathbf{B} / \mathbf{A}$ & T/D & Interaction \\
\hline \multicolumn{10}{|l|}{ Physical fitness } \\
\hline Grip strength (kg) & $27.8+0.9$ & $27.2+0.9$ & 0.343 & $21.6+0.7$ & $21.9+0.8$ & 0.608 & 0.882 & 0.000 & 0.575 \\
\hline Sit-up (times) & $7.2+0.8$ & $6.4+0.9$ & 0.161 & $6.2+0.8$ & $4.4+0.7$ & 0.149 & 0.085 & 0.075 & 0.501 \\
\hline Sit-and-reach flexibility $(\mathrm{cm})$ & $34.1+1.0$ & $36.7+1.4$ & 0.050 & $33.8+1.2$ & $31.1+1.2$ & 0.209 & 0.818 & 0.019 & 0.026 \\
\hline Eyes-open single leg stance (s) & $64.7+5.8$ & $57.1+6.3$ & 0.142 & $50.2+5.2$ & $65.4+6.2$ & 0.059 & 0.427 & 0.508 & 0.054 \\
\hline 10-m obstancle walk (s) & $9.2+0.4$ & $8.2+0.4$ & 0.000 & $9.9+0.2$ & $8.6+0.2$ & 0.001 & 0.000 & 0.086 & 0.628 \\
\hline Six-minutes walk (min) & $513.5+11.3$ & $504.3+11.9$ & 0.800 & $405.5+8.8$ & $420.0+9.6$ & 0.364 & 0.708 & 0.000 & 0.255 \\
\hline \multicolumn{10}{|l|}{ Blood chemistry } \\
\hline Fasting blood glucose $(\mathrm{mg} / \mathrm{dl})$ & $120.3+3.5$ & $123.6+3.2$ & 0.396 & $107.8+3.5$ & $107.0+5.1$ & 0.429 & 0.746 & 0.000 & 0.600 \\
\hline Total cholesterol (mg/dl) & $212.4+5.7$ & $222.6+6.4$ & 0.252 & $216.7+5.7$ & $216.3+7.4$ & 0.415 & 0.451 & 0.883 & 0.399 \\
\hline \multicolumn{10}{|c|}{ Brain function test (go/no-go test) } \\
\hline \multicolumn{10}{|c|}{ Response } \\
\hline Formation (ms) & $798.6+91.8$ & $668.9+88.4$ & 0.791 & $800.1+71.5$ & $659.4+56.8$ & 0.386 & 0.080 & 0.924 & 0.944 \\
\hline Differentiation (ms) & $764.1+102.6$ & $468.2+31.6$ & 0.100 & $578.9+50.7$ & $607.8+101.2$ & 0.531 & 0.138 & 0.653 & 0.045 \\
\hline Reverse Differentiation (ms) & $565.9+59.8$ & $437.4+16.7$ & 0.481 & $567.5+67.2$ & $551.0+82.6$ & 0.775 & 0.301 & 0.424 & 0.393 \\
\hline Average (ms) & $709.5+72.7$ & $524.8+34.5$ & 0.042 & $648.9+52.9$ & $606.1+68.1$ & 0.954 & 0.078 & 0.962 & 0.246 \\
\hline \multicolumn{10}{|l|}{ Times } \\
\hline Total number of misses (times) & $0.0+0.0$ & $0.0+0.0$ & - & $0.0+0.0$ & $0.0+0.0$ & - & - & - & - \\
\hline Total number of mistakes (times) & $6.8+0.7$ & $4.3+0.6$ & 0.018 & $8.2+0.8$ & $6.7+0.7$ & 0.337 & 0.000 & 0.013 & 0.503 \\
\hline Errors (times) & $6.8+0.7$ & $4.3+0.6$ & 0.018 & $8.2+0.8$ & $6.7+0.7$ & 0.337 & 0.001 & 0.013 & 0.503 \\
\hline
\end{tabular}

B/A: main effect of before and after, T/D main effect of Tabanan and Denpasar, Interaction: interaction effect between B/A and T/D, mean \pm se 
The use of pedometers can be a new experience for the participants. It can support and drive the participant to perform more activity and affect physical fitness. Observational studies showed that pedometer users significantly increased their physical activity by 2183 steps per day over the baseline value. The use of a pedometer is associated with significant increases in physical activity and significant decreases in body mass index and blood pressure. Simple step-count monitoring interventions should be prioritized to address the public health challenge of physical inactivity [21].

Physical fitness was based on handgrip strength, sit-up, sit-andreach flexibility, eyes-open single-leg stance, 10 -m obstacle walk and 6-min walk. In Tabanan regency, the results for the sit and reach flexibility and $10-\mathrm{m}$ obstacle walk significantly improved. In Denpasar, the results for the $10-\mathrm{m}$ obstacle walk significantly improved (table 2). Physical fitness can improve the health condition of individuals after the diagnosis of cancer. A study using a questionnaire among women after cancer diagnosis showed that more physically active women were diagnosed with localized breast cancer at a younger age and were more likely to be high school or college graduates than women with lower levels of postdiagnosis exercise [22]. This finding supports physical education for senior citizens, even if the participant was not diagnosed with cancer.

Blood chemistry was assessed based on blood glucose and total cholesterol. The results in Tabanan and Denpasar showed no significant difference after the program (table 2). The physical education component focused on physical and social activities for 8 mo. Food intake was not controlled in this study. The participants consumed food and beverages according to their culture and behavior. In Bali, most individuals are Hindu. They eat pork daily or during ceremonies. The physical education provided encouraged them to perform more activities in daily life to balance energy intake and energy expenditure.

Regarding brain function, in Tabanan, the go/no-go task response time was significantly shorter, and the number of error responses significantly decreased after the program (table 2). Physical education resulted in an improved mindset for senior citizens to perform physical activities regularly to achieve physical fitness. Physical fitness improved cardiorespiratory fitness, providing oxygen and nutrients to the brain and other body systems. An optimal nutrient supply can maintain brain function and other activities.

Physical activity has been noted to increase health and be used as a guideline for disease prevention, particularly for non-communicable diseases. This program can be used as a non-pharmacological therapy and is easy to perform by senior citizens. The use of Balinese dancing and singing are other factors that can be used to encourage active participation in physical activities.

Based on existing evidence, some public health organizations have issued physical activity guidelines for cancer prevention, generally recommending at least $30 \mathrm{~min}$ of moderate-to-vigorous intensity physical activity $>5 \mathrm{~d} / \mathrm{w}$ [23]. Recommendations to increase physical activity and maintain lean body weight should receive greater emphasis as part of a feasible approach for the prevention of colon cancer [24]. This means that physical activity for senior citizens in Bali is a method to prevent diseases.

Physical education is a tool to achieve higher physical fitness levels and can optimize cardiovascular and hormone systems. Physical activity appears to lower levels of biologically available sex hormones, which could lead to a decreased risk of hormone-related cancers, including cancers of the breast, endometrium, ovaries, prostate and testes [23]. This is related to a study of 120 women who visited the urban healthcare centers of Zarandieh that found that educational programs improve self-sufficiency and perceived susceptibility, severity and benefits and decrease perceived barriers, thus enhancing the awareness and function of individuals to perform physical examinations regularly [25].

Physical fitness can improve the blood chemistry of people, including senior citizens. Regular activity can maintain blood glucose and lipid profiles in a normal state. If the blood chemistry of senior citizens tends to increase, physical activities can reduce the rate of blood chemistry increase. Under this condition, the normal state of blood chemistry will support the cardiorespiratory system to work efficiently to transport nutrients for the brain and other bodies properly, and brain function can be maintained.

The activity of senior citizens should be performed in relaxed conditions. Physical activity programs should focus on regular activities rather than short vigorous activities. Recommendation on the types and amounts of physical activity needed to improve and maintain health in older adults. The recommended intensity of aerobic activity takes into account older adults' aerobic fitness; activities that maintain or increase flexibility are recommended, and balance exercises are recommended for older adults who are at risk of falls. In addition, older adults should have an activity plan for achieving recommended physical activity that integrates preventive and therapeutic recommendations. The promotion of physical activity in older adults should emphasize moderate-intensity aerobic activity, muscle-strengthening activity, reduced sedentary behavior, and risk management [16]. The intensity of physical activity for senior citizens should be applied individually based on individual capacity, but the physical activity must be performed regularly every week and sustainably. This was shown in a systematic review and meta-analysis of the association of high amounts of physical activity with mortality risk. The study compared the recommended (by public health authorities) level of physical activity with higher levels of physical activity. Our findings do not provide evidence for increased mortality risk with physical activity levels as high as seven times above the current recommended target range [26].

In other words, leisure activity is more effective at increasing the level of physical fitness. The significant inverse association between leisure-time physical activity and the incidence of colon cancer in women in this study is consistent with what has been found in men [24]. Leisure activity makes the subject more relaxed and reduces psychological stress other than physical stress and finally facilitates optimal brain function. Regular physical activity could represent an important and potent protective factor for cognitive decline and dementia in elderly persons [27]. In senior citizens, brain function can be decreased due to the aging process.

Senior citizens in Tabanan and Denpasar engaged in activities every day, even in urban and rural areas. Table 2 shows that there was no significant difference in the physical fitness test between the Denpasar and Tabanan groups. This means that the activities of individuals in both areas are quite similar. A cross-sectional design was used to associate urban residence with obesity, BMI, and transportation-related activity. The study reported that land-use mix had the strongest association with obesity (BMI_30 kg/m²); each additional hour spent in a car per day was associated with a $6 \%$ increase in the likelihood of obesity. Conversely, each additional kilometer walked per day was associated with a $4.8 \%$ reduction in the likelihood of obesity [28].

The physical education that was introduced to senior citizens in Tabanan and Denpasar was not enough. The use of activities popular in Balinese culture, such as Balinese dancing and singing, was attractive for senior citizens. These activities related to their activities and ability in the past and can still be done in their condition. Even so, more strategies need to be applied and adopted by the participant. This requires concern and commitment from senior citizens and awareness of the benefits of this program.

\section{CONCLUSION}

Health education using a Japanese-style healthcare program has beneficial effects for health promotion among senior citizens in urban and rural areas in Bali, Indonesia. Integration of programs with activities popular in Balinese culture can lead to active participation in physical activities. Physical fitness and blood chemistry brain function improved. This program can be used by other people in Bali or other countries. A longer time and more challenging program are needed for senior citizens to achieve health education goals.

\section{LIMITATION}

The Japanese Ministry of Education, Culture, Sports, Science, and Technology recommends that Japanese individuals, from elementary school students to elderly people, should measure their physical 
fitness. Therefore, they are used to taking physical fitness tests. However, elderly people in Indonesia have never experienced doing so and, therefore, may not easily understand how to do so. This factor may be one of the causes of Thailand's lower values in the test results. In the future, it is necessary to increase the number of subjects, to implement health education in more areas, and to find the improvement points of the health education system.

\section{ACKNOWLEDGEMENT}

Thank you for the person who participated in this program particularly for the senior citizen group in Tabanan Regency and Denpasar City, Bali, Indonesia.

\section{FUNDING}

Koji Terasawa is supported by grants-in-aid for scientific research (Kiban A: 16H02713) from the Ministry of Education, Culture, Sports, Science and Technology of Japan. The funder had no involvement in study design; the collection, analysis and interpretation of data; the writing of the report; or the decision to submit the article for publication.

\section{AUTHORS CONTRIBUTIONS}

IPGA, KT, TW, TK, YZ, KN and FS planned the experiment and collected the data. SJM, KN and ST performed the data analysis. IPGA and KT composed the article. All authors read and approved the final manuscript.

\section{CONFLICT OF INTERESTS}

There are no conflicts of interest.

\section{REFERENCES}

1. National Labor Survey of Indonesian Ministries: Indonesian Elderly Population Statistics; 2018.

2. Maruo SJ, Piasue N, Kalampakom S, Utthiya P, Sasimonthonkul $\mathrm{S}$, Tabuchi $\mathrm{H}$, et al. The effectiveness of a health promotion program using the international organization for standardization in klongyongand nikhompattana, Thailand. Asian J Pharm Clin Res 2020;13:1-6.

3. Fujimori S, Maruo SJ, Watanabe T, Taki N, Sasamori F, Kobayashi $\mathrm{K}$, et al. Effectiveness of a Japanese-style health program in Minowa town, Matsumoto city and Nagano city Japan. Int J Hum Right Healthcare 2020;13:1-17.

4. Rezende LFM, Garcia LMT, Mielke GI, Lee DH, Giovannucci E, Eluf-Neto J. Physical activity and preventable premature deaths from non-communicable diseases in Brazil. J Public Health (Oxf) 2019;41:253-60.

5. Andersen HPC, Bull LB, Guthold F, Haskell R, Ekelund W. Global physical activity level: surveilance progress, pitfalls, and procpects. Lancet 2012;380:247-57.

6. Maruo SJ, Sanongdetch W, Choeychom S, Chansirikarn S, Thrakul S, Phuphaibul R, et al. Comparing the effectiveness of health program in Thailand and Japan. J Nurs Care 2015;4:1-6.

7. Watanabe T, Terasawa K, Nakade K, Murata Y, Terasawa S, Kobayashi $\mathrm{T}$, et al. Influence of two different health promotion programs on walking steps, anthropometry, blood pressure, physical fitness, blood chemistry and brain function. I J Med Heal Sci 2015;5:170-81.

8. Murata Y, Nemoto K, Kobayashi T, Miyata Y, Terasawa S, Sasamori $\mathrm{F}$, at al. Effect of a two-year health program on brain function, physical fitness and blood chemistry. J Community Med Health Educ 2015;5:1-6.

9. Nakade K, Fujimori S, Watanabe T, Murata Y, Terasawa S, Maruo SJ, et al. A case study of health education from Nagano prefecture in Japan: the relationship between health education and medical expenses. J Community Med Health Educ 2017;7:1-6.
10. Niharika V. International to hyperlipidemia and its treatment: a review. Int J Curr Pharm Res 2017;9:6-14.

11. Anithha M, Monica RE, Monisha DM, Chella KJ. Prevalence of obesity and overweight among medicos in both male and female students. Asian J Pharm Clin Res 2016;9:1-3.

12. Beuchat MS, Sperisen N, Molnar P, Koçer S. Physical activity and cancer. Praxis (Bern 1994) 2018;107:965-70.

13. Purba EN, Santosa H, Siregar FA. The relationship of physical activity and obesity with the incidence of hypertension in adults aged 26-45 Y in medan. Maced J Med Sci 2019; 14:3464-8.

14. Ministry of Health of the Republic of Indonesia. Indonesian Health Profile; 2019.

15. Bali Province Health Office 2018. Directorate of family health director-general of public health Kementerian Kesehatan Ri; 2019.

16. Nelson ME, Rejeski WJ, Blair SN, Duncan PW, Judge JO. Physical activity and public health in older adults: recommendation from the american college of sports medicine and the American Heart Association. Circulation 2007;116:1094-105.

17. Frenzel A, Binder H, Walter N, Wirkner K, Loeffler M, Loeffler Wirth $\mathrm{H}$. The aging human body shape. NPJ Aging Mech Dis 2020;6:1-15.

18. Trichopoulou A, Gnardellis C, Lagiou A, Benetou V, Naska A, Trichopoulos D. Physical activity and energy intake selectively predict the waist-to-hip ratio in men but not in women. Am J Clin Nutr 2001;74:574-8.

19. Chao A, Connell CJ, Jacobs EJ, McCullough ML, Patel AV, Calle $\mathrm{AA}$, et al. Amount, type, and timing of recreational physical activity in relation to colon and rectal cancer in older adults: the cancer prevention study ii nutrition cohort. Cancer Epidemiol Biomarkers Prev 2004;3:2187-95.

20. Keimling M, Renehan AG, Behrens G, Fischer B, Hollenbeck AR, Cross AJ, et al. Comparison of associations of body mass index, abdominal adiposity, and risk of colorectal cancer in a large prospective cohort study. Cancer Epidemiol Biomarkers Prev 2013;22:1383-94.

21. Chaudhry UAR, Wahlich C, Fortescue R, Cook DG, Knightly R, Harris T. The effects of step-count monitoring interventions on physical activity: systematic review and meta-analysis of community-based randomised controlled trials in adults. Int J Behav Nutr Phys Act 2020;17:1-16.

22. Holick CN, Newcomb PA, Dietz AT, Ernstoff LT, Bersch AJ, Stampfer MJ, et al. Physical activity and survival after diagnosis of invasive breast cancer. Cancer Epidemiol Biomarkers Prev 2008; 17:379-86.

23. Friedenreich CM, Orenstein MR. Physical activity and cancer prevention: etiologic evidence and biological mechanisms. J Nutr 2002;132:3456-64.

24. Martınez ME, Giovannucci E, Spiegelman D, Hunter DJ, Willett WC, Colditz GA. Leisure-time physical activity, body size, and colon cancer in women. J Natl Cancer Inst 1997;89:948-55.

25. Karimy M, Gallali M, Niknami SH, Aminshokravi F, Tavafian SS. The effect of health education program based on Health Belief Model on the performance of Pap smear test among women referring to health care centers in Zarandieh. J Jahrom University Med Sci Spring 2012;10:47-53.

26. Blond K, Brinkløv CF, Ried Larsen M, Crippa A, Grøntved A. Association of high amounts of physical activity with mortality risk: a systematic review and meta-analysis. Br J Sports Med 2020;54:1195-201.

27. Frank LD, Andresen MA, Schmid TL. Obesity relationships with community design, physical activity, and time spent in cars. Am J Prev Med 2004;27:87-96.

28. Laurin D, Verreault R, Lindsay J, MacPherson K, Rockwood K. Physical activity and risk of cognitive impairment and dementia in elderly persons. Arch Neurol 2001;58:498-504. 